Sharif University of Technology
Scientia Iranica
Transactions E: Industrial Engineering
IRA IENTIA $\quad$\begin{tabular}{l} 
h / scientiairanica.sharif.edu \\
\hline
\end{tabular}

\title{
A heuristic method for choosing 'virtual best' DMUs to enhance the discrimination power of the augmented DEA model
}

\author{
M. Sadat Rezaei and A. Haeri* \\ School of Industrial Engineering, Iran University of Science \& Technology, Tehran, Iran. \\ Received 2 February 2019; received in revised form 7 August 2019; accepted 7 October 2019
}

\author{
KEYWORDS \\ Data envelopment \\ analysis; \\ Augmented DEA; \\ Performance \\ evaluation; \\ Hierarchical \\ clustering; \\ Virtual DMUs.
}

\begin{abstract}
Despite its intrinsic advantages and features that help elevate the discrimination power of the basic DEA (Data Envelopment Analysis) model, augmented DEA has two main drawbacks including unrealistic efficiency scores and a great distance between its efficiency scores and those obtained by the primary model. In this respect, this paper extends a heuristic method for dealing with both issues and improving the power of the augmented DEA model in performance evaluation. Since different virtual Decision Making Units (DMUs) yield various ranking results, the hierarchical clustering algorithm is applied, in this study, to select the best virtual DMUs to reduce the possibility of inappropriate efficiency scores. Finally, to demonstrate the superiority of the proposed approach over previous approaches in the literature, two numerical examples are provided.
\end{abstract}

(C) 2021 Sharif University of Technology. All rights reserved.

\section{Introduction}

Nowadays, the necessity of adopting an evaluation tool with appropriate performance under competitively changing markets is perceived more than ever to achieve the objectives of organizations. It is necessary to measure efficiency as a capability, successfully and without waste, to evaluate the performance of resources used in an organization. This evaluation plays a key role in providing periodic feedback to managers so as to determine the scope of improvement and ensure an organization's success [1].

The DEA method has a number of roles including ranking efficiency scores $[2,3]$ and providing an improvement plan [4-6]. In recent years, as a powerful

\footnotetext{
*. Corresponding author. Tel.: +9821 73225019; Fax: +982173225098

E-mail addresses: m.rezaee90@yahoo.com (M. Sadat Rezaei); ahaeri@iust.ac.ir (A.Haeri)
}

doi: $10.24200 /$ sci.2019.52890.3009 technique for performance evaluation, DEA has drawn great attention, while the basic type of DEA model is subject to some drawbacks despite its popularity. For instance, it uses variable weights derived directly from the data, and the weights are chosen such that the most favorable set of weights is allocated to each Decision Making Units (DMUs). In other words, the DMU allows utilizing its best multiplier weights to increase its efficiency. As a result, more than one efficient unit is usually obtained which cannot be discriminated. To solve this problem, several forms of DEA model have been developed to enhance the discrimination power and ability of the basic DEA model to rank the efficient DMUs. Appalla [7] extended the augmented DEA model to increase the discrimination power of the basic DEA by introducing a new virtual DMU generated by choosing the best values of each factor from the existing DMU base. However, the proposed augmented DEA by Appalla [7] has the following two main drawbacks:

- The presence of unrealistic efficiency scores;

- The presence of great distance between the efficiency 
scores obtained by the basic DEA and the scores obtained through the augmented DEA.

The above two notable issues indicate that presenting appropriate efficiency scores is a critical problem that must be addressed in performance evaluation; hence, many researchers have attempted to compute real and appropriate efficiency scores.

Another challenge associated with the DEA model is to find a way to incorporate judgment into it. Golany and Roll [8] proposed inserting engineering properties such as standards (i.e., virtual DMUs) into the evaluation with the aim of having a set of standard data to compare DMUs by simply expanding the reference set. The incorporation of standards is very useful as they can increase the potential of DMUs previously thought to be inefficient. In addition, according to Golany and Roll [8], creating standards is a challenge, but one of the best attributes of DEA is that it identifies the 'excellence that can be acquired from different combinations of inputs and outputs'.

Data mining is a new area where organizations can obtain competitive advantage. Through the process of data mining, useful information can be extracted from large databases, which is important and vital in today's business and marketing since this extracted information can assist decision-makers in making better and more intelligent decisions $[9,10]$. Data mining consists of a number of common classes of tasks, in which cluster analysis is considered the main task, and a common method for data analysis which seeks to classify a set of elements so that these elements in the same cluster bear much more similarity to each other than to those in other clusters [11].

According to the enumerated matters, the present work proposes a new heuristic method to enhance the discrimination power of the augmented DEA model by creating a set of potential virtual DMUs and employing a data mining approach for DMU data. To do so, cluster analysis as a popular data mining approach is applied. The analysis of a dataset is enhanced using cluster analysis, and with the help of the information obtained through clustering, virtual DMUs can be created in a more coherent manner than previous approaches in the literature. This approach helps prevent the problem of inappropriate efficiency scores. The main questions that this study is going to answer are listed below:

1. What values should be considered for input and output factors of virtual DMUs?

2. How many virtual DMUs should be added?

The remaining structure of this paper is given below. Section 2 expresses a review of the literature regarding the augmented DEA. Section 3 presents the DEA model along with the application of augmented
DEA. The extended approach is introduced in Section 4. In Section 5, a case study and a numerical example are presented to show how the extended heuristic method outperforms previous approaches in the literature. Section 6 is devoted to results and discussion. Finally, Section 7 includes a conclusion of this research.

\section{Literature review}

Over the past years, various models and techniques have been developed to enhance the discrimination power of the DEA model using augmented DEA. Shokr et al. [12] developed an Augmented Common Weight Data Envelopment Analysis (ACWDEA) model for material selection by high-tech industries where both qualitative and quantitative criteria are involved. Their proposed model enjoys greater discrimination power which can produce full ranking vectors. In addition, it is capable to determine the weights of qualitative and quantitative criteria precisely. Shen et al. [13] introduced an augmented DEA model to eliminate the poor discrimination power of the basic DEA considering the distances to both efficient and anti-efficient frontiers. In the provided model, the standard DEA model and the inverted model of DEA as two linear programming models were solved concurrently to present further information regarding frontiers. Wu et al. [14] proposed a new approach to the evaluation and selection of suppliers called Augmented Imprecise DEA (AIDEA) which could rank suppliers effectively despite using imprecise data such as ordinal data and interval data. Besides, AIDEA model could increase the discrimination power; however, it gave weight flexibility to the DMUs and allowed inappropriate DMUs to become false positive candidates. Considering deviation variable framework of the variable-returns-to-scale method, Ghasemi et al. [15] extended an augmented form of the DEA model to improve the discriminatory power of the DEA model. Wu and Blackhurst [16] employed an augmented DEA model for evaluating and selecting suppliers. The provided approach included virtual DMUs produced by choosing the best value of one factor and the average values of the remaining factors from the inputs and outputs, and weight constraints proposed to decrease the possibility of getting unsuitable input and output factor weights. Hou et al. [17] proposed a novel model to improve DMUs evaluation by introducing two virtual DMUs, namely ideal point and anti-ideal point DMUs. The former was based on efficiency, while the latter was based on fairness. Noorizadeh et al. [18] presented an augmented DEA model considering both non-discretionary inputs and dual-role factors. The proposed model was applied only for choosing a DMU from efficient DMUs. Kianfar et al. [19] combined clustering with Analytic Hierarchy Process (AHP) to 
eliminate the poor discrimination capability of the DEA to prioritize efficient DMUs. Hatefi and Razmi [20] provided an AIDEA to evaluate a set of suppliers. Mahdiloo et al. [21] provided an approach to ranking suppliers employing both undesirable outputs and dual-role factors. The proposed model was run with a virtual DMU which improved the discrimination power of the primary model.

Some of the previous research studies have used the augmented DEA as a performance evaluation tool for different DMUs. For instance, Rezaie et al. [2] used it to improve the discrimination power of DEA to rank organizational resources properly. They introduced a virtual DMU with high outputs and low inputs. Haeri [22] applied augmented DEA to boost the discrimination power of DEA to rank photovoltaic solar cells technologies correctly. Based on this technique, two virtual DMUs which are assumed to have the best and the worst efficiency scores were added to the existing DMU base. Rezaee et al. [23] employed an augmented DEA model to promote the discrimination capability of DEA (CCR) model to evaluate the performance of automotive vendors. In the provided model, they introduced two virtual DMUs with the highest and lowest efficiency scores and added them to the basic model. Geng et al. [24] presented a two-phase remanufacturing decision-making method for complex products. In the first phase, an augmented DEA was utilized to assess the efficiencies of the pre-selected components. Ouellette and Yan [25] developed a dynamic version of the DEA model. They used the augmented DEA model to measure technical and allocative efficiencies. Table 1 demonstrates a comprehensive classification of different approaches to handling virtual DMUs in the literature. Khalili-Damghani and Fadaei [26] introduced two virtual DMUs, termed ideal virtual DMU and anti-ideal virtual DMU, to enhance the discrimination power of DEA.

In other studies $[27,28]$, weight restrictions were considered to decrease efficient DMUs and improve discrimination among DMUs. Golany and Roll [8] stated that weight restriction and virtual DMUs impacted on the efficiency scores in the same direction. In other words, by tightening the bounds on weights or adding virtual DMUs, efficiency scores could not be enhanced. Virtual DMUs have the ability to turn the DMUs that have been previously considered efficient into inefficient ones and even turn the DMUs that have been previously considered inefficient into lower efficiency scores. Dyson and Thanassoulis [29] developed an approach termed direct weight restrictions for increasing discrimination among DMUs. In this approach, the restrictions impose numerical limits on the weights. Charnes et al. [30] proposed the cone ratio model that would yield at least one efficient DMU. Thompson et al. [31] proposed "The Assurance Region
I" which would result in at least one efficient DMU and "The Assurance Region II" which would impose restrictions on the ratio between input and output weights. In this case, it is not assured that there will be at least one efficient DMU. Bal et al. [32] developed an approach based on the dispersion of weights in the DEA model to increase the discrimination among efficient DMUs. Hatami-Marbini et al. [33] employed dual weight constraints to remove low discrimination power in DEA. Liu [34] proposed an approach for a fuzzy two-stage DEA model in which the weights were restricted in ranges. He used the assurance region to reduce weight flexibility. Ennen and Batool [35] applied weights restrictions for inputs and outputs in the DEA procedure to increase the ability of DEA to differentiate between performance levels. Wang et al. [36] developed a method to rank DMUs by imposing an appropriate minimum weight constraint on all input and output factors. Ebrahimi et al. [37] presented a modified type of DEA model to evaluate the performance of real-life systems that includes various types of weight restrictions and imprecise data. The developed approach eliminates the drawbacks of existing models and provides more reliable outcomes.

The assurance region approach can be considered as another approach to promoting the discrimination capability of the DEA model. In this method, weights of input and output factors are restricted by upper and lower bounds. Haeri and Rezaie [4] proposed a three-step assurance region method to calculate upper and lower bounds of the input and output factors. In the first step of the proposed method, the basic (unbounded) DEA model is run. In the second step, optimal solutions of the unbounded DEA model are used to compute the average weights of input and output factors. Finally, in the third step, two sets of constraints are added to the basic DEA model to restrict weights between upper and lower bounds.

\subsection{Research gaps and contributions}

According to the literature review on the augmented DEA, the research gap and the main contribution of this work are explained as follows:

First, with respect to the previous studies, it can be realized that augmented DEA has mostly been used for increasing the discrimination power of DEA model while two issues remain not considered. The first problem is that the new obtained efficiency scores using augmented DEA model are usually unreal. Moreover, the distance between the efficiency scores of the basic DEA and those obtained by augmented DEA model is great. Accordingly, in this paper, a heuristic method is extended to cope with both issues and improve the discrimination power of the augmented DEA model in performance evaluation. 
Table 1. Different approaches of handling virtual Decision Making Units (DMUs) in literature.

\begin{tabular}{|c|c|c|}
\hline Ref. & The number of virtual DMUs & Input and output factors' value of virtual DMUs \\
\hline Rezaie et al. [2] & One virtual DMU & $\begin{array}{l}\text { The best values of each factor from all DMUs } \\
\text { (high outputs and low inputs) }\end{array}$ \\
\hline Appalla $[7]$ & One virtual DMU & $\begin{array}{l}\text { The best values of each factor from all DMUs } \\
\text { (high outputs and low inputs) }\end{array}$ \\
\hline Wu et al. [14] & One virtual DMU & $\begin{array}{l}\text { The best values of each factor from all DMUs } \\
\text { (high outputs and low inputs) }\end{array}$ \\
\hline Wu and Blackhurst [16] & $\begin{array}{l}\text { Equal to the number of input } \\
\text { and output factors }\end{array}$ & $\begin{array}{l}\text { The best value of one factor and the average } \\
\text { values of the remaining factors from all DMUs }\end{array}$ \\
\hline Noorizadeh et al. [18] & One virtual DMU & The best values of each factor from the efficient DMUs \\
\hline Hatefi and Razmi [20] & One virtual DMU & $\begin{array}{l}\text { The best values of each factor from all DMUs } \\
\text { (high outputs and low inputs) }\end{array}$ \\
\hline Mahdiloo et al. [21] & One virtual DMU & The best values of each factor from the efficient DMUs \\
\hline Haeri $[22]$ & Two virtual DMUs & $\begin{array}{l}\text { 1st virtual DMU: The best values of each factor } \\
\text { from all DMUs (high outputs and low inputs) } \\
\text { 2nd virtual DMU: The worst values of each factor } \\
\text { from all DMUs (low outputs and high inputs) }\end{array}$ \\
\hline Rezaee et al. [23] & Two virtual DMUs & $\begin{array}{l}\text { 1st virtual DMU: The best values of each factor } \\
\text { from all DMUs (high outputs and low inputs) } \\
\text { 2nd virtual DMU: The worst values of each } \\
\text { factor from all DMUs (low outputs and high inputs) }\end{array}$ \\
\hline Geng et al. [24] & $\begin{array}{l}\text { Equal to the number of input } \\
\text { and output factors }\end{array}$ & $\begin{array}{l}\text { The best value of one factor and the average values of } \\
\text { the remaining factors from all DMUs }\end{array}$ \\
\hline $\begin{array}{l}\text { Khalili-Damghani } \\
\text { and Fadaei }[26]\end{array}$ & Two virtual DMUs & $\begin{array}{l}\text { Ideal virtual DMU: The best target formed according to } \\
\text { the observed DMUsanti-ideal virtual DMU: The worst } \\
\text { target formed according to the observed DMUs }\end{array}$ \\
\hline This paper & $\begin{array}{l}\text { Equal to the number of } \\
\text { optimal clusters }\end{array}$ & The best values of each factor from the optimal clusters \\
\hline
\end{tabular}

Second, different virtual DMUs lead to different results for DMUs ranking; therefore, the proposed method in this study tries to choose the best virtual DMUs in order to reduce the possibility of having inappropriate efficiency scores. As shown in Table 1, most of the previous studies have taken into account only one virtual DMU for increasing the capability of DEA which is mostly created by selecting the best value of each factor from all DMUs. In other words, for each output factor, the maximum value and for each input factor, the minimum value are selected. On the other hand, there are some articles that have considered two 
virtual DMUs with the best and worst performances, and there are also few researches that have taken into account the number of virtual DMUs equal to the number of input and output factors. To the best of the authors' knowledge, there is not any reference that employs a data-mining approach for DMU data (i.e., clustering analysis) to determine the number and values of input and output factors of virtual DMUs.

Third, since the addition of a new DMU is the same as that of weight restriction to the dual model (weight model), this study will not make a computational effort for weight restrictions and it improves discrimination power only by creating new virtual DMUs.

\section{Augmented Data Envelopment Analysis (DEA)}

DEA as a non-parametric method was initially introduced by Charnes et al. [38] and it is mainly used for evaluating the efficiency of a set of DMUs regarded as independent units to convert the same inputs into identical outputs. Generally, smaller value for input and larger value for output are preferable. In this method, the efficiency of a DMU is computed as follows:

$$
\text { Efficiency }=\frac{\text { weighted sum of outputs }}{\text { weighted sum of inputs }} \text {. }
$$

Each DMU can pick its best weights to increase its efficiency score. A DMU with an efficiency score of one is efficient, while a DMU with an efficiency score less than one is inefficient. The basic type of DEA model for evaluating a set of DMUs' efficiency is called CCR model which has two drawbacks including lack of discrimination among efficient DMUs and assignment of unreal weights to input and output factors; in other words, a small (or zero) weight is given to an important factor or a big weight is given to a factor of lower importance. To cope with the aforementioned problems, Appalla [7] provided an augmented version of basic DEA model termed augmented DEA. In this approach, a new virtual DMU called the 'virtual best' $\mathrm{DMU}$ is defined. Given that the lower and higher values are more desirable for inputs and outputs, respectively, the input and output factors of virtual ideal DMU are generated by choosing the minimum value of each input factor and the maximum value of each output factor from the existing DMU base. Based on this method, the efficient frontier of the model changes and, hence, the efficiency of each DMU is achieved according to the efficient frontier of the 'virtual best' DMU.

\subsection{Basic DEA model}

The following notations are used for formulating the DEA models:

$\begin{array}{ll}j & \text { Index of DMUs, } j=\{1,2, \ldots, n\} \\ r & \text { Index of outputs, } r=\{1,2, \ldots, s\} \\ i & \text { Index of outputs, } i=\{1,2, \ldots, m\} \\ x_{i j} & \text { The amount of input } i \text { for DMU } j \\ y_{r j} & \text { The amount of output } r \text { for DMU } j \\ y_{r}^{*} & \text { The maximum value of output } r \text { in the } \\ & \text { DMU base } \\ x_{i}^{*} & \text { The minimum value of input } i \text { in the } \\ & \text { DMU base } \\ u_{r} & \text { Weight of output } r \\ v_{i} & \text { Weight of input } i\end{array}$

The efficiency of $D M U_{o}$ can be obtained by solving the following model:

$$
\operatorname{Max} \sum_{r=1}^{s} u_{r} y_{r o} \text {. }
$$

Subject to:

$$
\begin{aligned}
& \sum_{i=1}^{m} v_{i} x_{i o}=1, \\
& \sum_{r=1}^{s} u_{r} y_{r j}-\sum_{i=1}^{m} v_{i} x_{i j} \leq 0 \quad j=1, \ldots, n, \\
& u_{r} \geq 0 \\
& v_{i} \geq 0 .
\end{aligned}
$$

\subsection{Augmented DEA model}

The mathematical model of the augmented DEA model using the above-mentioned notations is given below:

$$
\operatorname{Max} \sum_{r=1}^{s} u_{r} y_{r \circ} \text {. }
$$

Subject to:

$$
\begin{aligned}
& \sum_{i=1}^{m} V_{i} x_{i \circ}=1, \\
& \sum_{r=1}^{s} u_{r} y_{r j}-\sum_{i=1}^{m} v_{i} x_{i j} \leq 0 \quad j=1, \ldots, n, \\
& \sum_{r=1}^{s} u_{r} y_{r}^{*}-\sum_{i=1}^{m} v_{i} x_{i}^{*} \leq 0 .
\end{aligned}
$$

$y_{r}^{*}$ and $x_{i}^{*}$ form the input and output factors of the 'virtual best' DMU. The DMU's efficiency is measured by using the above mathematical model and can then be used to rank the DMUs.

\section{Proposed approach}

In this paper, a heuristic method is developed to enhance the discrimination power of the augmented 
DEA model in performance evaluation. The major objective of this method is choosing the best virtual DMUs in order to reduce the possibility of having inappropriate efficiency scores. DEA analysis combined with clustering analysis is a very interesting tool for creating a set of potential virtual DMUs. By grouping DMUs into clusters, the visualization of input and output factors as well as the analysis of data set are improved and with the help of obtained information through clustering, virtual DMUs can be created in a more coherent manner than the previous approaches in the literature. This prevents the problem of having inappropriate efficiency scores. Therefore, in this section, a four-step algorithm is introduced to generate a set of potential virtual DMUs and to enhance the discrimination power of the augmented DEA employing the clustering approach of DMU's data. For this purpose, first, cluster analysis is applied so that DMUs can be grouped into clusters. In order to perform cluster analysis, the SPSS statistical software is used. Then, $n$ virtual DMUs are created by choosing the best values of each factor from $n$ optimal clusters determined in the previous step. Next, the new produced virtual DMUs are added to the existing DMUs base and finally, the DEA (CCR) model is run to obtain new efficiency scores for DMUs. The proposed algorithm is applied through the following steps.

\subsection{Step 1. Implementation of the clustering algorithm on the existing DMU's data}

The purpose of this step is to group DMUs into clusters based on their inputs and outputs. In this regard, clustering as a popular data mining approach is used in this study to classify a set of DMUs into a number of different groups such that:

- DMUs in each group are similar to each other.

- DMUs of one group are different from those of other groups.

Consequently, for the given DMU set, the greater the differences between the groups, the more homogeneous each group is, and vice versa. To the best of the authors' knowledge, this paper is the first to create virtual DMUs by employing clustering approach; therefore, this step of the proposed approach is new and can be considered as one of the innovations of this research.

In order to perform cluster analysis, the SPSS statistical software is used in this step. SPSS as a widely used tool for data analysis in social science covers many statistical analysis tests, filters and prepares data for an analysis, creates various charts, carries out analysis of the relationships between two and more factors, classifies data, and creates clusters. This software offers three methods for the cluster analysis (k-means cluster, hierarchical cluster, and two-step cluster) according to the research needs. Furthermore, SPSS carries out an analysis and concludes with higher precision when working with complex relationships in data. Additionally, it provides graphics with more analytical features, thus facilitating a discussion of the resulting output from the clustering process [39]. Clustering algorithm of DMU data using SPSS can be described stepwise as follows.

\subsubsection{Selection of the type of clustering technique}

Since the task of clustering is based on individual's perception, there are many methods for achieving this goal. Hierarchical clustering is known as one of the most popular clustering algorithms. In this paper, hierarchical clustering method has been adopted for the following reasons [40]:

- The main characteristic of hierarchical clustering is the analysis of grouping in the data simultaneously over a variety of scales;

- The results of hierarchical clustering are typically provided in a dendrogram which is a diagram that can be utilized as a visualization tool in monitoring the hierarchical relationship between objects and controlling the decision-making process;

- In hierarchical clustering, results are reproducible;

- By interpreting the dendrogram, one may stop and manage at whatever number of clusters he/she finds appropriate.

Hierarchical clustering technique aims to create a hierarchy of clusters and it can be divided into two main types including agglomerative and divisive. Agglomerative clustering begins with individual elements which can be aggregated into clusters, while divisive clustering begins with all data and divides them into partitions. To determine which clusters must be merged for agglomerative clustering or where a cluster must be separated for divisive one, it is essential that the distance between pairs of elements be measured. This study uses the agglomerative hierarchical clustering method to group DMUs into clusters.

\subsubsection{Selection of a measure of similarity}

The distance between the two points (DMUs) is considered as a measure of similarity. There are some commonly used metrics such as Manhattan distance, Mahalanobis distance, Maximum distance, Euclidean distance, and squared Euclidean distance. Euclidean distance or the squared Euclidean distance is the most common distance measure in published papers. Therefore, this study applies the squared Euclidean distance between two DMUs as a measure of similarity, as stated below:

$$
d_{\text {euc }} D(x . y)=\sum_{i=1}^{p}\left(x_{i}-y_{i}\right)^{2} .
$$




\subsubsection{Selection of the type of clustering method for the selected technique}

To calculate the distance between two clusters, various methods have been proposed such as nearest neighbor, farthest neighbor, average linkage method, ward's method, and centroid method. The different algorithms for hierarchical clustering vary mostly according to how the distance between the two clusters is calculated. In centroid method used in this study, each cluster is replaced by an average point (DMU), which is the centroid of that cluster.

\subsubsection{Determination of the number of clusters} SPSS has an output viewer window that contains all the outputs we can generate. In the first step of the cluster procedure, the proximity matrix will be produced in SPSS' output. This matrix gives the squared Euclidean distance calculated between DMUs. Agglomeration schedule that follows the proximity matrix in the output shows the clusters obtained at each stage using hierarchical clustering.

\subsubsection{Determination of the number of optimal clusters}

There are various indicators for determining the number of optimal clusters. R-SQUARED (RS) is one of the most widely used statistics for evaluating the cluster solution and determining the number of optimal clusters. RS helps measure which groups differ from each other and which groups are homogeneous, as stated below:

$$
\begin{aligned}
R S & =\frac{S S_{b}}{S S_{t}} \\
& =\frac{\text { sum of squares between }- \text { group }}{S S_{b}+S S_{w}(\text { sum of squares within }- \text { group })} \\
0 & \leq R S \leq 1
\end{aligned}
$$

The values of RS range from 0 to 1 , with 0 and 1 denoting no differences and maximum differences among clusters, respectively.

\subsection{Step 2. Creation of $n$ virtual DMUs by choosing the best value of each factor from $n$ optimal clusters}

In this step, virtual DMUs are generated based on optimal clusters. Clusters with the maximum RS are considered as a basis for producing virtual DMUs. Thus, given that there are $n$ optimal clusters, $n$ virtual DMUs will be generated. Virtual DMUs are generated by choosing the best value of each factor from the optimal clusters. Since the higher value is more desirable for outputs while the lower value is more desirable for inputs, the input and output factors of the virtual ideal DMU are created by selecting the minimum value of each input factor and the maximum value of each output factor from the optimal clusters.

\subsection{Step 3. Addition of the created virtual $D M U s$ to the existing DMU's data}

The efficient frontier of the basic DEA model is changed by adding a new virtual best DMU and, hence, the DMU's efficiency is achieved according to the efficient frontier of the new virtual DMU. Therefore, the discrimination power of classical DEA is enhanced in such a way that DMUs previously thought of as efficient will be inefficient.

\subsection{Step 4. Running of the DEA (CCR) model and calculation of new efficiency scores}

Finally, to obtain new efficiency scores for DMUs by considering virtual DMUs, DEA (CCR) model is run. The logic of each step is explained in Table 2.

Business Process Model and Notation (BPMN) is a graphical illustration of very complex processes as a means of understanding, analyzing, and making positive changes to processes. Usage of BPMN will help visualize the processes and make better decisions. The most important leverage of BPMN over other techniques is that it is standard with a well-defined set of rules. Hence, it makes collaboration much easier since it is familiar to many business analysts. Additionally, this standard is supported by most modeling tools which make it much easier to share and edit, even in case various software products are used. All the mentioned matters make BPMN the most popular business process modeling technique in the time being. Accordingly, BPMN is used to make the process of the proposed heuristic method for choosing 'virtual best' DMUs more understandable (see Figure 1). Figure 2 shows all the BPMN elements targeted in the transformation from the above-mentioned steps to BPMN.

Explanation about the symbols of Figure 2 is given as follows. Task represents the lowest level activ-

Table 2. The logic of each step.

\begin{tabular}{cl}
\hline Steps & \multicolumn{1}{c}{ Logic } \\
\hline Step 1 & The aim of this step is to group DMUs such that each cluster is as homogeneous as possible \\
Step 2 & Optimal clusters provide the ability to create the best virtual DMUs \\
Step 3 & The addition of virtual DMU increases the capability of the basic DEA \\
Step 4 & The purpose of this step is to calculate new efficiency scores based on the added virtual DMUs \\
\hline
\end{tabular}




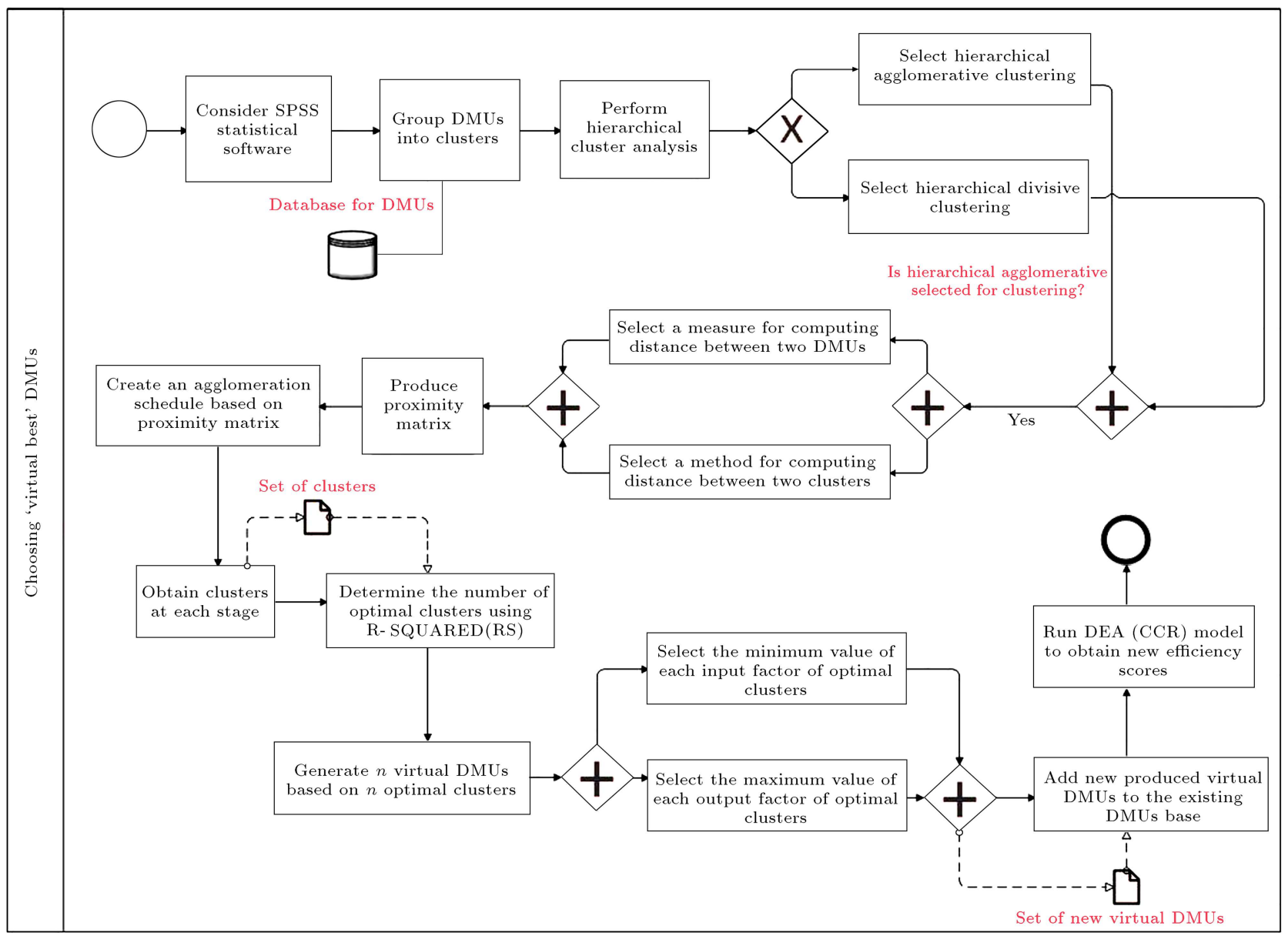

Figure 1. The process of choosing 'virtual best' DMUs.

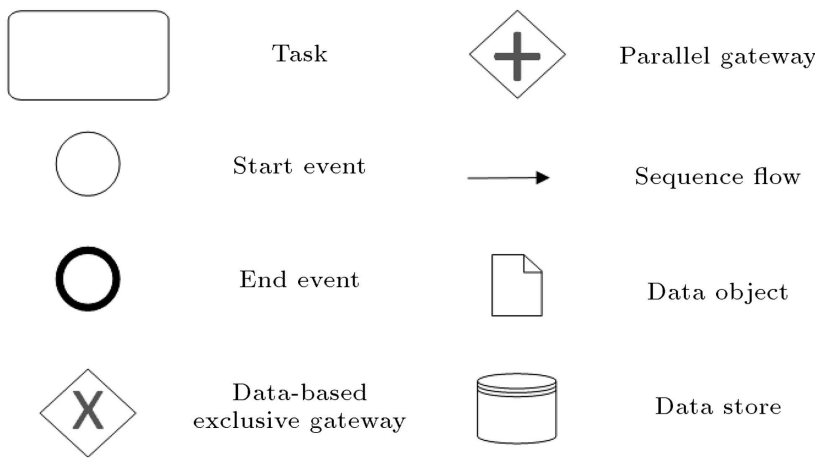

Figure 2. Overview of applied Business Process Model and Notation (BPMN) elements.

ity within a process flow. Start and end events point to the occurrence and result of a process, respectively. Data-based exclusive gateway creates alternative flows in a process so that only one of the paths can be chosen. Parallel gateway creates parallel paths so that no decision is required. Sequence flow links two elements of a process and indicates in which order the activities are performed. Data object provides the information that activities require and finally, data store displays the information banks related to the process.

\section{Numerical examples}

To demonstrate the application and superiority of the extended approach over the previous approaches, two numerical examples are borrowed from the literature. The data collection procedure of this study is expressed below:

First, the purpose of data collection is determined. The objective of this paper is to enhance the discrimination power of the augmented DEA model in performance evaluation by creating a set of potential virtual DMUs based on employing clustering approach of DMU data.

Second, sources of data are determined in compliance with our stated purpose. Various sources such as online sites and relevant articles are investigated to determine suitable sources.

Third, the data is collected. The data sources for input and output factors are obtained from secondary sources. Relevant providers of secondary data include Wu and Blackhurst [16] and Cook and Kress [41]. 
In the first example, the results of a new approach are compared with those of previous approaches used in Wu and Blackhurst [16] and Appalla [7] papers. In the second example, the data from Cook and Kress [41] is considered.

\subsection{Example 1}

The dataset of the first example has been taken from a global-scale company that provides communication and aviation electronics. It maintains headquarters and manufacturing operations in the United States with extra places in Europe, Mexico, and Australia with more than 19,000 staff worldwide. The company has emphasized improving the supplier performance. In this regard, Wu and Blackhurst [16] provided an approach to supplier evaluation and selection of this company. In this case application, there are 10 DMUs (suppliers): two inputs namely price and proprietary design partnerships and two output factors namely delivery performance and quality. The input and output factors have been selected by consulting the managers in the strategic sourcing division of the company which seemed to be very important to the company. The inputs and outputs selected in this study are not inherently related. For example, price as an input factor represents the amount paid by a buyer, while the input of proprietary design partnerships indicates the agreements established between the supplier and the company concerning the use of technology in product design. On the other hand, the outputs of quality and delivery performance are the benefits derived by the buyer. In this paper, this case application is used to demonstrate the superiority of our proposed approach over the approach used in the study of $\mathrm{Wu}$ and Blackhurst [16]. The normalized values of the inputs and outputs for the suppliers are given in Table 3. In the first step, the basic DEA model is utilized to measure the efficiency scores. The results and efficiency scores are given in Table 3 .
As shown in Table 3, there are more than one efficient DMU which means that the basic type of DEA model cannot prioritize DMUs properly and the results of this model are not so useful. In order to solve this problem, the augmented DEA model introduced in Section 3.2 is used because it transcends this drawback upon creating a virtual DMU.

Table 4 shows that in the basic DEA context, S01, S02, S03, S05, and S09 are ranked as the best DMUs, while in the augmented DEA context, S02 is not among the top five DMUs. On the other hand, the basic DEA ranks S07 and S10 as the worst DMUs while the augmented DEA ranks S06 and S08 besides S07 and S10 as the worst DMUs, indicating that the basic DEA performance is not on a par with the augmented DEA model. In addition, as can be seen in Table 4, there is a great distance between the efficiency scores of S02, S06, and S08 in the basic DEA model and their scores in the augmented DEA model. In other words, the obtained efficiency scores for theses DMUs through augmented DEA are unreal. To overcome this problem,

Table 4. A comparison between the basic DEA model and augmented DEA.

\begin{tabular}{ccc}
\hline DMUs & $\begin{array}{c}\text { The basic } \\
\text { DEA model }\end{array}$ & $\begin{array}{c}\text { Augmented } \\
\text { DEA model }\end{array}$ \\
\hline S01 & 1 & 0.98 \\
S02 & $\mathbf{1}$ & $\mathbf{0 . 6}$ \\
S03 & 1 & 0.98 \\
S04 & 0.66 & 0.52 \\
S05 & 1 & 0.99 \\
S06 & $\mathbf{0 . 6 8}$ & $\mathbf{0 . 3 9}$ \\
S07 & 0.34 & 0.34 \\
S08 & $\mathbf{0 . 9 4}$ & $\mathbf{0 . 3 3}$ \\
S09 & 1 & 0.99 \\
S10 & 0.34 & 0.33 \\
\hline
\end{tabular}

Table 3. Input and output data and efficiency scores of 10 DMUs using the basic DEA model.

\begin{tabular}{ccccccc}
\hline & \multicolumn{2}{c}{ Input } & & \multicolumn{2}{c}{ Output } & \\
\cline { 2 - 3 } DMUs & $\begin{array}{c}\text { Proprietary design } \\
\text { partnerships }\end{array}$ & Price & & Quality & $\begin{array}{c}\text { Delivery } \\
\text { performance }\end{array}$ & Efficiency scores \\
\hline S01 & 1 & 0.0715 & & 0.4285 & 0.98 & 1 \\
S02 & 0.998 & 0.1173 & & 0.7143 & 0.991 & 1 \\
S03 & 0.336 & 0.7105 & & 0.8571 & 0.98 & 1 \\
S04 & 0.65 & 1 & & 1 & 0.999 & 0.66 \\
S05 & 0.336 & 0.1801 & & 0.6428 & 0.985 & 1 \\
S06 & 1 & 0.1801 & & 0.431 & 0.98 & 0.68 \\
S07 & 0.998 & 0.8992 & & 0.2585 & 0.995 & 0.34 \\
S08 & 0.999 & 0.2111 & & 0.9286 & 0.98 & 0.94 \\
S09 & 0.336 & 0.2124 & & 0.4 & 0.99 & 1 \\
S10 & 0.999 & 0.952 & 0.3448 & 0.99 & 0.34 \\
\hline
\end{tabular}


the four-step algorithm described in Section 4 is implemented using SPSS statistical software. With respect to this algorithm, first, a hierarchical agglomerative clustering is applied to group 10 DMUs into clusters based on their inputs and outputs. To do so, the squared Euclidean distance and centroid method are applied to calculate the distance between two DMUs and the distance between two clusters, respectively. Table 5 indicates the proximity matrix that provides the squared Euclidean distance calculated between 10 DMUs. As shown in Table 5, S07 and S10 have the shortest distance (approximately 0.010).

Table 6 illustrates the agglomeration schedule which presents how the hierarchical cluster analysis increasingly clusters the DMUs. According to Table 6 , each row displays a stage at which two DMUs are merged to form a cluster through an algorithm controlled by the distance and centroid linkage. The number of stages is one, less than the number of DMUs. The schedule gives all of the stages in which the clusters are merged until there is only one cluster remaining after the last stage. The coefficient at each stage illustrates the distance between the two clusters being merged.

"Stage cluster first appears" in Table 6 shows the clusters created throughout the previous stages and they first appear in this stage. For instance, at the first stage of agglomeration schedule (see Table 6), S7 is combined with S10 since these two DMUs have the smallest squared Euclidean distance. The two zeros under Cluster 1 and Cluster 2 indicate that neither DMU has been previously clustered. The cluster created by joining S7 and S10 next appears in Stage 8 . In Stage 8, Number 6 under Cluster 1 and Number 1 under Cluster 2 indicate that the clusters created in Stages 1 and 6 join in this stage. The resulting cluster appears next in Stage 9.

The results of hierarchical clustering are usually illustrated in dendrogram or icicle plot. Figure 3 shows a dendrogram of the results of Table 6 . Dendrogram as a tree diagram is often utilized to demonstrate the arrangement of the clusters generated by hierarchical clustering. In this diagram, the distance or dissimilarity between clusters is represented by the horizontal

Table 5. Squared Euclidean distance calculated between 10 DMUs.

\begin{tabular}{ccccccccccc}
\hline \multirow{2}{*}{ Case } & \multicolumn{8}{c}{ Squared euclidean distance } \\
\cline { 2 - 11 } & $\mathbf{1 : S 1}$ & $\mathbf{2 : S 2}$ & $\mathbf{3 : S 3}$ & $\mathbf{4 : S 4}$ & $\mathbf{5 : S 5}$ & $\mathbf{6 : S 6}$ & $\mathbf{7 : S 7}$ & $\mathbf{8 : S 8}$ & $\mathbf{9 : S 9}$ & $\mathbf{1 0 : S 1 0}$ \\
\hline $\mathbf{1 : S 1}$ & 0 & 0.084 & 1.033 & 1.312 & 0.499 & 0.012 & 0.714 & 0.270 & 0.462 & 0.782 \\
$\mathbf{2 : S 2}$ & 0.084 & 0 & 0.811 & 0.982 & 0.447 & 0.084 & 0.819 & 0.055 & 0.546 & 0.833 \\
$\mathbf{3 : S 3}$ & 1.033 & 0.811 & 0 & 0.203 & 0.327 & 0.904 & 0.832 & 0.694 & 0.457 & 0.760 \\
$\mathbf{4 : S 4}$ & 1.312 & 0.982 & 0.203 & 0 & 0.899 & 1.119 & 0.681 & 0.750 & 1.079 & 0.553 \\
$\mathbf{5 : S 5}$ & 0.499 & 0.447 & 0.327 & 0.899 & 0 & 0.486 & 1.103 & 0.522 & 0.060 & 1.124 \\
$\mathbf{6 : S 6}$ & 0.012 & 0.084 & 0.904 & 1.119 & 0.486 & 0 & 0.547 & 0.249 & 0.443 & 0.603 \\
$\mathbf{7 : S 7}$ & 0.714 & 0.819 & 0.832 & 0.681 & 1.103 & 0.547 & 0 & 0.923 & 0.930 & 0.010 \\
$\mathbf{8 : S 8}$ & 0.270 & 0.055 & 0.694 & 0.750 & 0.552 & 0.294 & 0.923 & 0 & 0.719 & 0.890 \\
$\mathbf{9 : S 9}$ & 0.462 & 0.546 & 0.457 & 1.079 & 0.060 & 0.443 & 0.930 & 0.719 & 0 & 0.990 \\
$\mathbf{1 0 : S 1 0}$ & 0.782 & 0.833 & 0.760 & 0.553 & 1.124 & 0.603 & 0.010 & 0.890 & 0.990 & 0 \\
\hline
\end{tabular}

Table 6. Agglomeration schedule of 10 DMUs.

\begin{tabular}{ccccccc}
\hline \multirow{2}{*}{ Stage } & \multicolumn{2}{c}{ Cluster combined } & \multirow{2}{*}{ Coefficients } & \multicolumn{2}{c}{ Stage cluster first appears } & Next stage \\
\cline { 2 - 3 } & Cluster 1 & Cluster 2 & & Cluster 1 & Cluster 2 & \\
\hline 1 & 7 & 10 & 0.010 & 0 & 0 & 8 \\
2 & 1 & 6 & 0.012 & 0 & 0 & 5 \\
3 & 2 & 8 & 0.055 & 0 & 0 & 5 \\
4 & 5 & 9 & 0.060 & 0 & 0 & 7 \\
5 & 1 & 2 & 0.155 & 2 & 3 & 7 \\
6 & 3 & 4 & 0.203 & 0 & 0 & 8 \\
7 & 1 & 5 & 0.453 & 5 & 4 & 9 \\
8 & 3 & 7 & 0.653 & 6 & 1 & 9 \\
9 & 1 & 3 & 0.532 & 7 & 8 & 0 \\
\hline
\end{tabular}




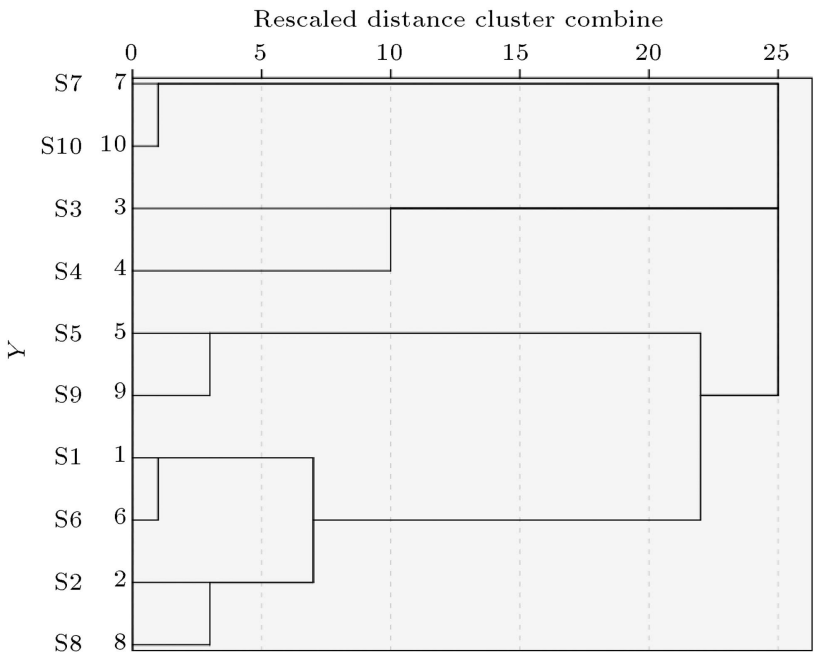

Figure 3. Dendrogram using centroid linkage.

axis and the elements and clusters are represented by the vertical axis. In order to interpret a dendrogram, the height at which any two elements reach each other should be considered. For instance, according to Figure 3, the height of the link that joins S7 and S10 together is the lowest; thus, they are the most similar. The next two most similar elements are S1 and S6.

Compared to dendrogram, it is easier in an icicle plot to read which elements belong to which clusters since the element labels reveal exactly where the clusters are specified. Figure 4 presents icicle plot from clustering of 10 DMUs. The column placed between two DMUs indicates the number of common clusters between them. As can be observed from Figure 4,
Table 7. Clusters obtained at each stage using hierarchical clustering.

\begin{tabular}{cc}
\hline Stage & Clusters \\
\hline 1 & $(\mathrm{~S} 7, \mathrm{~S} 10)$ \\
2 & $(\mathrm{~S} 1, \mathrm{~S} 6)$ \\
3 & $(\mathrm{~S} 2, \mathrm{~S} 8)$ \\
4 & $(\mathrm{~S} 5, \mathrm{~S} 9)$ \\
5 & $(\mathrm{~S} 1, \mathrm{~S} 6, \mathrm{~S} 2, \mathrm{~S} 8)$ \\
6 & $(\mathrm{~S} 3, \mathrm{~S} 4)$ \\
7 & $(\mathrm{~S} 1, \mathrm{~S} 6, \mathrm{~S} 2, \mathrm{~S} 8, \mathrm{~S} 5, \mathrm{~S} 9)$ \\
8 & $(\mathrm{~S} 3, \mathrm{~S} 4, \mathrm{~S} 7, \mathrm{~S} 10)$ \\
9 & $(\mathrm{~S} 1, \mathrm{~S} 6, \mathrm{~S} 2, \mathrm{~S} 8, \mathrm{~S} 5, \mathrm{~S} 9, \mathrm{~S} 3, \mathrm{~S} 4, \mathrm{~S} 7, \mathrm{~S} 10)$ \\
\hline
\end{tabular}

the most common column lies between S7 and S10, which means that S7 and S10 belong to the first stage and they are the most similar ones. Next, the most common cluster lies between $\mathrm{S} 1$ and $\mathrm{S} 6$ which belong to the second stage.

Table 7 shows the clusters obtained at each stage using hierarchical clustering. According to Table 7, six statuses can be considered for clustering. Then, RS as the most widely used statistic is applied to determine the number of optimal clusters.

According to Table 8, Statuses 1 and 2 have the maximum differences among clusters; therefore, they can be considered as a basis to produce virtual DMUs. As mentioned previously, the higher value is more desirable for outputs and the lower value is more desirable for inputs. Thus, the input and output factors

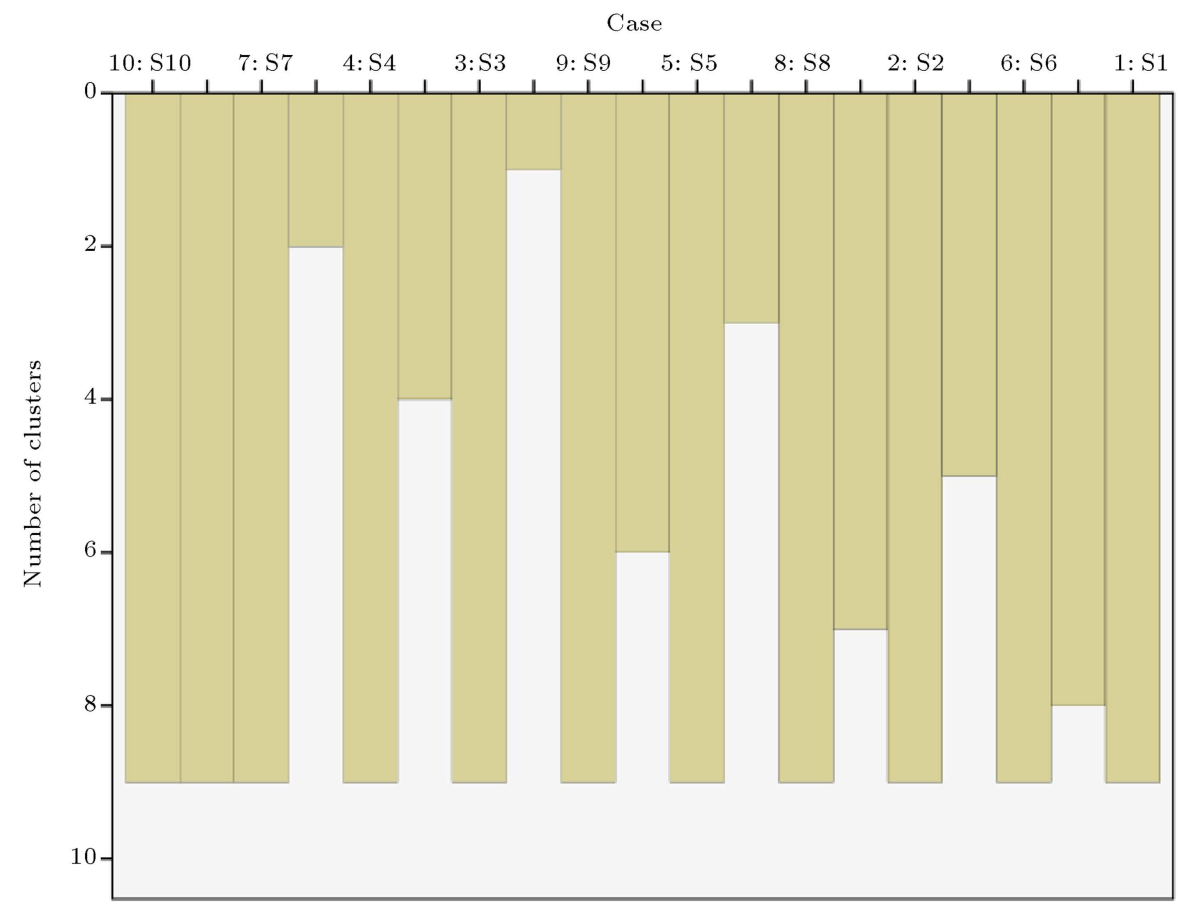

Figure 4. Icicle plot. 
Table 8. Six selected statuses and the value of RS for each one.

\begin{tabular}{|c|c|c|}
\hline Status & Clusters & RS \\
\hline 1 & $(\mathrm{~S} 7, \mathrm{~S} 10)(\mathrm{S} 1, \mathrm{~S} 6)(\mathrm{S} 2, \mathrm{~S} 8)(\mathrm{S} 5, \mathrm{~S} 9)(\mathrm{S} 3, \mathrm{~S} 4)$ & 0.941 \\
\hline 2 & $(\mathrm{~S} 1, \mathrm{~S} 6, \mathrm{~S} 2, \mathrm{~S} 8)(\mathrm{S} 7, \mathrm{~S} 10)(\mathrm{S} 5, \mathrm{~S} 9)(\mathrm{S} 3, \mathrm{~S} 4)$ & 0.886 \\
\hline 3 & $(\mathrm{~S} 1, \mathrm{~S} 6, \mathrm{~S} 2, \mathrm{~S} 8, \mathrm{~S} 5, \mathrm{~S} 9)(\mathrm{S} 3, \mathrm{~S} 4, \mathrm{~S} 7, \mathrm{~S} 10)$ & 0.447 \\
\hline 4 & $(\mathrm{~S} 1, \mathrm{~S} 6, \mathrm{~S} 2, \mathrm{~S} 8, \mathrm{~S} 5, \mathrm{~S} 9)(\mathrm{S} 7, \mathrm{~S} 10)(\mathrm{S} 3, \mathrm{~S} 4)$ & 0.675 \\
\hline 5 & $(\mathrm{~S} 3, \mathrm{~S} 4, \mathrm{~S} 7, \mathrm{~S} 10)(\mathrm{S} 1, \mathrm{~S} 6)(\mathrm{S} 2, \mathrm{~S} 8)(\mathrm{S} 5, \mathrm{~S} 9)$ & 0.712 \\
\hline 6 & $(\mathrm{~S} 1, \mathrm{~S} 6, \mathrm{~S} 2, \mathrm{~S} 8)(\mathrm{S} 5, \mathrm{~S} 9)(\mathrm{S} 3, \mathrm{~S} 4, \mathrm{~S} 7, \mathrm{~S} 10)$ & 0.658 \\
\hline
\end{tabular}

of virtual ideal DMU are generated by choosing the minimum value of each input factor and the maximum value of each output factor from the existing clusters in Statuses 1 and 2 .

Additionally, since there are five clusters in Status 1 and four clusters in Status 2, five virtual DMUs and four virtual DMUs are derived from the data of clusters, respectively. As shown in Table 9, five virtual DMUs are created for Status 1 and four virtual DMUs for Status 2. The newly produced virtual DMUs are added to the existing DMUs base and then, the DEA (CCR) model is run to obtain new efficiency scores for 10 DMUs. A comparison between the basic DEA model, augmented DEA, Wu and Blackhurst [16] approach and heuristic method is provided in Table 10. For receiving the best result, efficiency scores are calculated in both statues.

As shown in Table 10, the number of efficient DMUs in Status 2 is less than that of efficient DMUs in Status 1; therefore, Status 2 is chosen as the one with the best result. Table 10 includes some interesting findings in connection with the comparison of the four above approaches. These findings are as follows:

- It is interesting to note that the heuristic method exhibits greater discrimination power than Appalla [7] approach (augmented DEA model).

- The distance between the efficiency scores of the basic DEA model and the efficiency scores of the heuristic method (Status 2) has been minimized and the discrimination power of Appalla [7] approach (augmented DEA model) has improved through the proposed approach.

- In Wu and Blackhurst [16] method, two enhancements have been applied to the basic DEA model including virtual DMUs and weight constraints which require more computational effort, while in the heuristic method, computational effort for weight constraints has been eliminated and only virtual DMUs have been added to the basic DEA model.

Table 9. Created virtual Decision Making Units (DMUs) for the first numerical example.

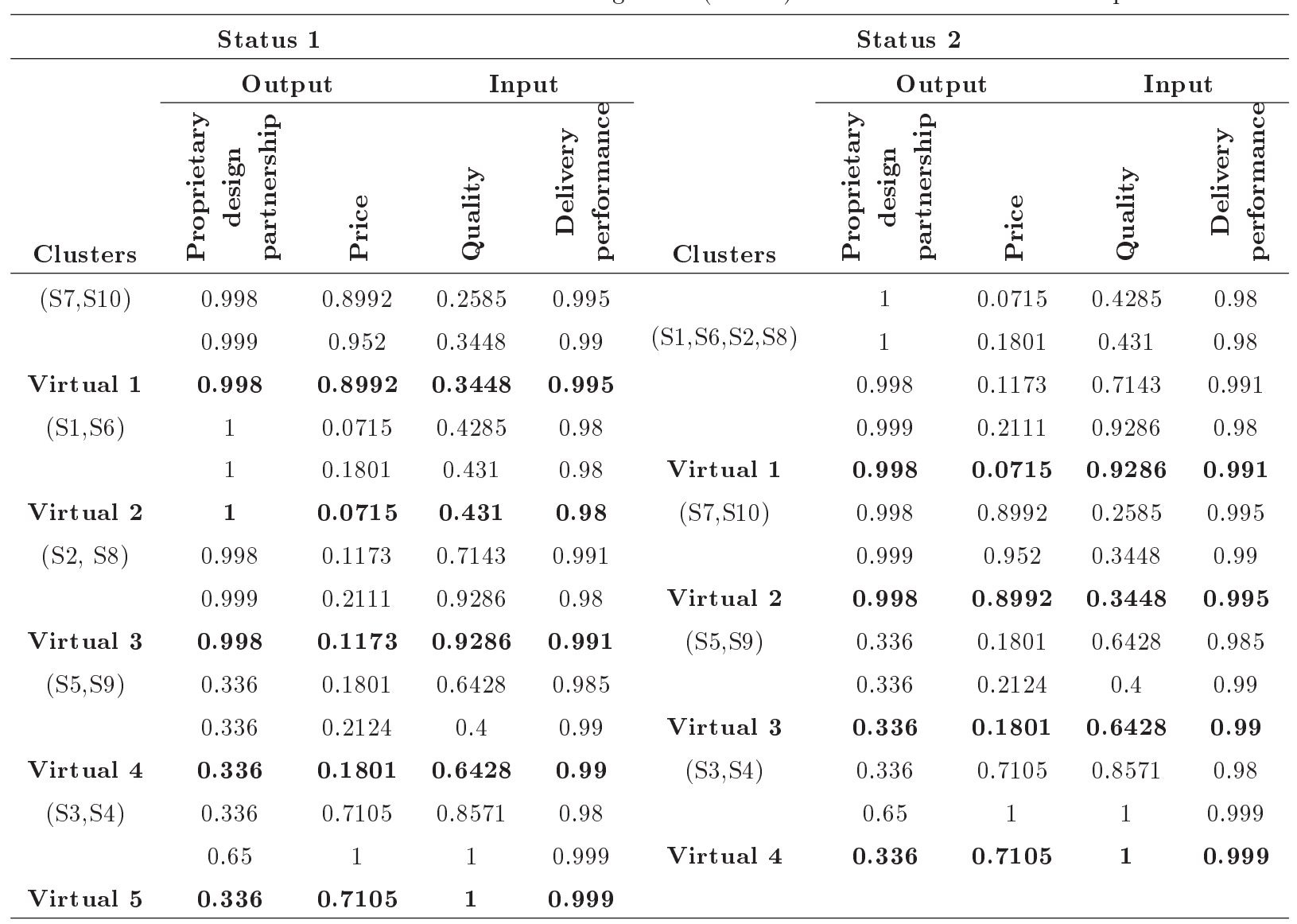


Table 10. Comparison results of the four approaches.

\begin{tabular}{|c|c|c|c|c|c|}
\hline \multirow[t]{2}{*}{ DMUs } & \multirow{2}{*}{$\begin{array}{l}\text { CCR DEA } \\
\text { mode }\end{array}$} & \multirow{2}{*}{$\begin{array}{l}\text { Augmented DEA } \\
\text { (Appalla [7]) }\end{array}$} & \multirow{2}{*}{$\begin{array}{c}\text { Wu and } \\
\text { Blackhurst }[16] \\
\text { approach }\end{array}$} & \multicolumn{2}{|c|}{ The heuristic method } \\
\hline & & & & Status 1 & Status 2 \\
\hline 1 & 1 & 0.98 & 0.95 & 1 & 0.99 \\
\hline 2 & 1 & 0.6 & 0.85 & 0.92 & 0.84 \\
\hline 3 & 1 & 0.98 & 0.98 & 0.98 & 0.98 \\
\hline 4 & 0.66 & 0.52 & 0.66 & 0.59 & 0.59 \\
\hline 5 & 1 & 0.99 & 1 & 1 & 1 \\
\hline 6 & 0.68 & 0.39 & 0.61 & 0.68 & 0.68 \\
\hline 7 & 0.34 & 0.34 & 0.34 & 0.34 & 0.34 \\
\hline 8 & 0.94 & 0.33 & 0.86 & 0.81 & 0.76 \\
\hline 9 & 1 & 0.99 & 0.99 & 0.99 & 0.99 \\
\hline 10 & 0.34 & 0.33 & 0.33 & 0.34 & 0.34 \\
\hline
\end{tabular}

Table 11. Input and output data and efficiency scores of 12 DMUs.

\begin{tabular}{|c|c|c|c|c|c|c|c|}
\hline \multirow[t]{2}{*}{ DMUs } & \multicolumn{3}{|c|}{ Input } & \multicolumn{2}{|c|}{ Output } & \multirow{2}{*}{$\begin{array}{l}\text { CCR DEA } \\
\text { model }\end{array}$} & \multirow{2}{*}{$\begin{array}{c}\text { Augmented DEA } \\
\text { (Appalla [7]) }\end{array}$} \\
\hline & $x 1$ & $x 2$ & $x 3$ & $y 1$ & $y^{2}$ & & \\
\hline S01 & 0.2889 & 0.0285 & 0.0034 & 0.0519 & 0.6248 & 0.7498 & 0.4919 \\
\hline S02 & 0.2454 & 0.0176 & 0.0025 & 0.057 & 0.5075 & 0.919 & 0.6353 \\
\hline S03 & 0.3492 & 0.0218 & 0.0017 & 0.0586 & 0.4849 & 0.6797 & 0.4595 \\
\hline S04 & 0.2312 & 0.0092 & 0.0034 & 0.0544 & 0.5528 & 1 & 0.6566 \\
\hline S05 & 0.2479 & 0.0092 & 0.0008 & 0.0586 & 0.3685 & 1 & 0.7071 \\
\hline S06 & 0.2973 & 0.0201 & 0.0101 & 0.0653 & 0.892 & 0.9615 & 0.6809 \\
\hline $\mathrm{S} 07$ & 0.4481 & 0.0109 & 0.0042 & 0.0561 & 0.3786 & 0.8173 & 0.5726 \\
\hline S08 & 0.227 & 0.0235 & 0 & 0.0611 & 0.4899 & 1 & 0.7374 \\
\hline S09 & 0.2663 & 0.0168 & 0 & 0.0586 & 0.8953 & 1 & 0.763 \\
\hline S10 & 0.3677 & 0.0494 & 0.0008 & 0.0578 & 0.8936 & 0.723 & 0.5517 \\
\hline S11 & 0.2663 & 0.0168 & 0 & 0.0168 & 0.2889 & 0.3227 & 0.2462 \\
\hline $\mathrm{S} 12$ & 0.3677 & 0.0494 & 0.0008 & 0.0829 & 1 & 1 & 0.6173 \\
\hline
\end{tabular}

\subsection{Example 2}

To demonstrate the applicability of the extended method, the data from Cook and Kress [41] is considered. In this case application, there are 12 DMUs, three inputs, and two outputs. The normalized values of each factor are given in Table 11. The basic DEA model is applied to the data set which results in more than one efficient DMU (see Table 11). To solve this problem, the augmented DEA model is used.

As can be seen in Table 11, there is a great distance between the efficiency scores of the basic DEA model and those obtained through the augmented DEA. To overcome this problem, the heuristic method proposed in this study is exploited. For this purpose, the hierarchical clustering is first performed. Table 12 shows the clusters obtained at each stage using hierarchical clustering. According to Table 12, two statuses can be considered for clustering. For determining the number of optimal clusters, RS is used. As shown in Table 13, Status 1 has the maximum differences among clusters; therefore, it can be considered as a basis to produce virtual DMUs. Three virtual DMUs are created for this case with respect to the input and output data of clusters (see Table 14). Three virtual DMUs are added to the existing DMUs base and then, the DEA (CCR) model is run to obtain new efficiency scores for 12 DMUs. The comparative study results are shown in Table 15. 
Table 12. Clusters obtained at each stage using hierarchical clustering.

\begin{tabular}{cc}
\hline Stage & Clusters \\
\hline 1 & $(\mathrm{~S} 2, \mathrm{~S} 8)$ \\
2 & $(\mathrm{~S} 6, \mathrm{~S} 9)$ \\
3 & $(\mathrm{~S} 2, \mathrm{~S} 8, \mathrm{~S} 4)$ \\
4 & $(\mathrm{~S} 6, \mathrm{~S} 9, \mathrm{~S} 10)$ \\
5 & $(\mathrm{~S} 5, \mathrm{~S} 11)$ \\
6 & $(\mathrm{~S} 2, \mathrm{~S} 8, \mathrm{~S} 4, \mathrm{~S} 3)$ \\
7 & $(\mathrm{~S} 1, \mathrm{~S} 2, \mathrm{~S} 8, \mathrm{~S} 4, \mathrm{~S} 3)$ \\
8 & $(\mathrm{~S} 6, \mathrm{~S} 9, \mathrm{~S} 10, \mathrm{~S} 12)$ \\
9 & $(\mathrm{~S} 5, \mathrm{~S} 11, \mathrm{~S} 7)$ \\
10 & $(\mathrm{~S} 1, \mathrm{~S} 2, \mathrm{~S} 8, \mathrm{~S} 4, \mathrm{~S} 3, \mathrm{~S} 5, \mathrm{~S} 11, \mathrm{~S} 7)$ \\
11 & $(\mathrm{~S} 1, \mathrm{~S} 2, \mathrm{~S} 8, \mathrm{~S} 4, \mathrm{~S} 3, \mathrm{~S} 5, \mathrm{~S} 11, \mathrm{~S} 7, \mathrm{~S} 6, \mathrm{~S} 9, \mathrm{~S} 10, \mathrm{~S} 12)$ \\
\hline
\end{tabular}

Table 15 shows the enhanced discrimination power of the heuristic method over Appalla [7] approach (augmented DEA) to rank DMUs.

\section{Results and discussion}

This study aims to extend the application of the augmented DEA upon creating a set of potential virtual DMUs based on the cluster analysis of DMU's data in order to reduce the possibility of having inappropriate efficiency scores. The proposed heuristic method in this study can address the problems of the augmented DEA model where DMUs may have unrealistic efficiency scores or great distance with the efficiency scores obtained by the basic DEA. In order to demonstrate the application of the proposed method in performance evaluation context, it is implemented on two numerical examples which are taken from the literature.

In total, the DMUs in the first and second examples can be classified into groups in terms of efficiency scores obtained through the basic DEA model (see Table 16). As can be observed from Table 16, considering efficiency scores, 10 DMUs in Example 1 are classified into four groups and 12 DMUs in Example 2 are classified into six groups. The specific point in Table 16 is that in the second example, the range of efficiency scores is more varied than in the first example.

In the first example, the algorithm of the proposed method is implemented on a dataset from a commu- nication and aviation electronics company that has emphasized the supplier performance. This example consists of 10 DMUs (suppliers), two inputs, and two outputs. According to the algorithm explained in Section 4, first, a hierarchical agglomerative clustering is applied to group 10 suppliers into clusters based on their inputs and outputs which results in creation of six statuses for clustering. Among the created statuses, Statuses 1 and 2 are determined as optimal clusters since they have the maximum values of $\mathrm{RS}\left(\mathrm{RS}_{\text {statues } 1}\right.$ $=0.941$, and $\mathrm{RS}_{\text {statues } 2}=0.886$ ) among the other statues. Then, five virtual DMUs based on five clusters in Status 1 and four virtual DMUs based on four clusters in Status 2 are created by choosing the best values of each factor from the existing clusters in each status. Next, the newly created virtual DMUs are added to the existing DMU's data and finally, the DEA (CCR) model is run to obtain new efficiency scores for 10 suppliers. According to the efficiency results, the number of efficient DMUs in Status 2 is less than the number of efficient DMUs in Status 1; therefore, Status 2 is chosen as the best result for comparison experiments. According to Table 10, the full rankings are achieved through augmented DEA and the heuristic method and the discrimination powers of these two approaches are quite higher than the basic DEA model as a distinctive rank is assigned to each DMU. However, it can be concluded from contents of Table 10 that the efficiency scores obtained from the heuristic method are more consistent with the results of the basic DEA model and, therefore, they are considered to be more realistic than the efficiency scores obtained by the augmented DEA. Figure 5 provides comparative results of the performance of three approaches towards the efficiency scores of 10 suppliers. As can be observed from Figure 5, there is a considerable distance between the efficiency scores obtained by the basic DEA model and those of the augmented DEA, while by applying the heuristic method and adding a set of potential virtual DMUs to the existing DMU's data, this great distance has been reduced and therefore, the discrimination power of the augmented DEA has been enhanced through the proposed approach.

In the second example, the algorithm of the proposed heuristic method is implemented on a dataset from Cook and Kress [41] including 12 DMUs, three inputs, and two outputs. First, 12 DMUs are grouped into clusters considering their in puts and outputs which result in the creation of two statuses for clustering.

Table 13. Two selected statuses.

\begin{tabular}{|c|c|c|}
\hline Status & Clusters & RS \\
\hline 1 & $(\mathrm{~S} 1, \mathrm{~S} 2, \mathrm{~S} 8, \mathrm{~S} 4, \mathrm{~S} 3)(\mathrm{S} 6, \mathrm{~S} 9, \mathrm{~S} 10, \mathrm{~S} 12)(\mathrm{S} 5, \mathrm{~S} 11, \mathrm{~S} 7)$ & 0.897 \\
\hline 2 & $(\mathrm{~S} 6, \mathrm{~S} 9, \mathrm{~S} 10, \mathrm{~S} 12)(\mathrm{S} 1, \mathrm{~S} 2, \mathrm{~S} 8, \mathrm{~S} 4, \mathrm{~S} 3, \mathrm{~S} 5, \mathrm{~S} 11, \mathrm{~S} 7)$ & 0.797 \\
\hline
\end{tabular}


Table 14. Three Virtual Decision Making Units (DMUs) for the second numerical example.

\begin{tabular}{cccccc}
\hline Clusters & $\boldsymbol{X}_{\mathbf{1}}$ & $\boldsymbol{X}_{\mathbf{2}}$ & $\boldsymbol{X}_{\mathbf{3}}$ & $\boldsymbol{Y}_{\mathbf{1}}$ & $\boldsymbol{Y}_{\mathbf{2}}$ \\
\hline & 0.2889 & 0.0285 & 0.0034 & 0.0519 & 0.6248 \\
& 0.2454 & 0.0176 & 0.0025 & 0.057 & 0.5075 \\
& 0.227 & 0.0235 & 0 & 0.0611 & 0.4899 \\
& 0.2312 & 0.0092 & 0.0034 & 0.0544 & 0.5528 \\
& 0.3492 & 0.0218 & 0.0017 & 0.0586 & 0.4849 \\
Virtual 1 & $\mathbf{0 . 2 2 7}$ & $\mathbf{0 . 0 0 9 2}$ & $\mathbf{0}$ & $\mathbf{0 . 0 6 1 1}$ & $\mathbf{0 . 6 2 4 8}$ \\
& & & & & \\
(S6,S9,S10,S12) & 0.2663 & 0.0168 & 0 & 0.0586 & 0.8953 \\
& 0.3677 & 0.0494 & 0.0008 & 0.0578 & 0.8936 \\
& 0.3677 & 0.0494 & 0.0008 & 0.0829 & 1 \\
& & & & & \\
Virtual 2 & $\mathbf{0 . 2 6 6 3}$ & $\mathbf{0 . 0 1 6 8}$ & $\mathbf{0}$ & $\mathbf{0 . 0 8 2 9}$ & $\mathbf{1}$ \\
& & & & & \\
& 0.2479 & 0.0092 & 0.0008 & 0.0586 & 0.3685 \\
Virtual 3 & $\mathbf{0 . 2 4 7 9}$ & $\mathbf{0 . 0 0 9}$ & $\mathbf{0}$ & $\mathbf{0 . 0 5 8 6}$ & $\mathbf{0 . 3 7 8 6}$ \\
\hline & & & & &
\end{tabular}

Table 15. Comparison results between CCR DEA model, augmented DEA and the heuristic method.

\begin{tabular}{cccc}
\hline DMUs & $\begin{array}{c}\text { CCR DEA } \\
\text { model }\end{array}$ & $\begin{array}{c}\text { Augmented DEA } \\
\text { (Appalla [7]) }\end{array}$ & $\begin{array}{c}\text { The heuristic } \\
\text { method }\end{array}$ \\
\hline 1 & 0.7498 & 0.4919 & 0.5773 \\
2 & 0.919 & 0.6353 & 0.7455 \\
3 & 0.6797 & 0.4595 & 0.541 \\
4 & 1 & 0.6566 & 0.8904 \\
5 & 1 & 0.7071 & 0.9589 \\
6 & 0.9615 & 0.6809 & 0.799 \\
7 & 0.8173 & 0.5726 & 0.7766 \\
8 & 1 & 0.7374 & 0.8653 \\
9 & 1 & 0.763 & 0.8953 \\
10 & 0.723 & 0.5517 & 0.6473 \\
11 & 0.3227 & 0.2462 & 0.2889 \\
12 & 1 & 0.6173 & 0.7244 \\
\hline
\end{tabular}

Status 1 is selected as optimal clusters since it has the maximum value of $\mathrm{RS}\left(\mathrm{RS}_{\text {statues } 1}=0.897\right)$ compared to Status $2\left(\mathrm{RS}_{\text {statues } 2}=0.797\right)$. Then, three virtual DMUs are created based on the three clusters in Status 1 by choosing the best values of each factor from the existing clusters in this status. Next, the newly created virtual DMUs are added to the existing DMU's data and finally, the DEA (CCR) model is run to obtain new efficiency scores for 12 DMUs. Even though the augmented DEA increases the discriminatory ability of the basic DEA, the efficiency scores obtained by the augmented DEA do not reflect the real efficiency of the DMUs obtained by CCR DEA and there is a considerable distance between their efficiency scores. As Figure 6 represents, the heuristic method has advantages over the augmented DEA model since through 
Table 16. Detected groups for the first and second examples based on efficiency scores by the basic DEA model.

\begin{tabular}{|c|c|c|}
\hline Groups & Example 1 & Example 2 \\
\hline 1st Group & Five efficient DMUs of S1, S2, S3, S5, and S9 (ES = 1). & $\begin{array}{l}\text { Five efficient DMUs of } 4,5,8,9, \\
\text { and } 12(\mathrm{ES}=1) .\end{array}$ \\
\hline 2nd Group & S8 whose efficiency score is equal to 0.94 . & $\begin{array}{c}\text { Two DMUs of } 2 \text { and } 6 \text { whose } \\
\text { efficiency scores are } 0.919 \text { and } \\
0.9615 \text {, respectively. }\end{array}$ \\
\hline 3rd Group & $\begin{array}{l}\text { Two DMUs of } \mathrm{S} 4 \text { and } \mathrm{S} 6 \text { whose efficiency } \\
\text { scores are } 0.66 \text { and } 0.68 \text {, respectively. }\end{array}$ & DMU7 whose efficiency score is equal to 0.8173 . \\
\hline 4th Group & Two DMUs of S7 and S10 (ES = 0.34). & $\begin{array}{c}\text { Two DMUs of } 1 \text { and } 10 \text { whose } \\
\text { efficiency scores are } 0.7498 \text { and } \\
\text { 0.723, respectively. }\end{array}$ \\
\hline 5th Group & - & DMU3 whose efficiency score is equal to 0.6797 . \\
\hline 6th Group & - & DMU11 whose efficiency score is equal to 0.3227 . \\
\hline
\end{tabular}

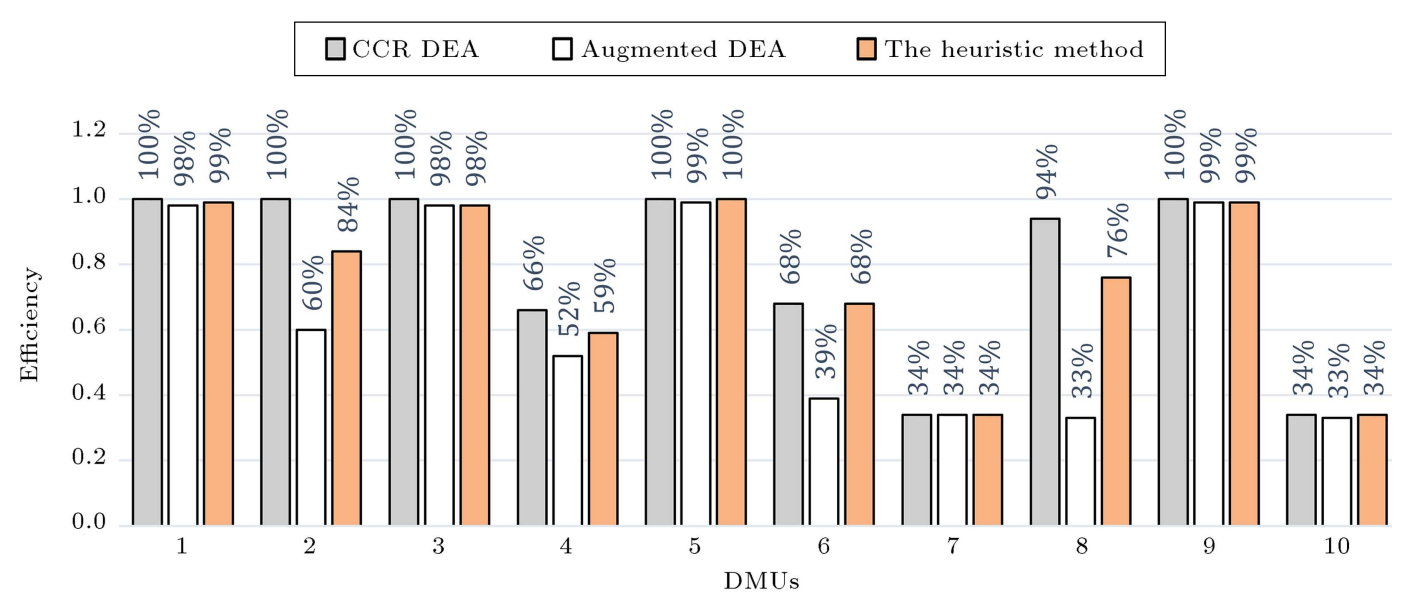

Figure 5. Comparative results of the performance of three approaches towards the efficiency scores of 10 DMUs.

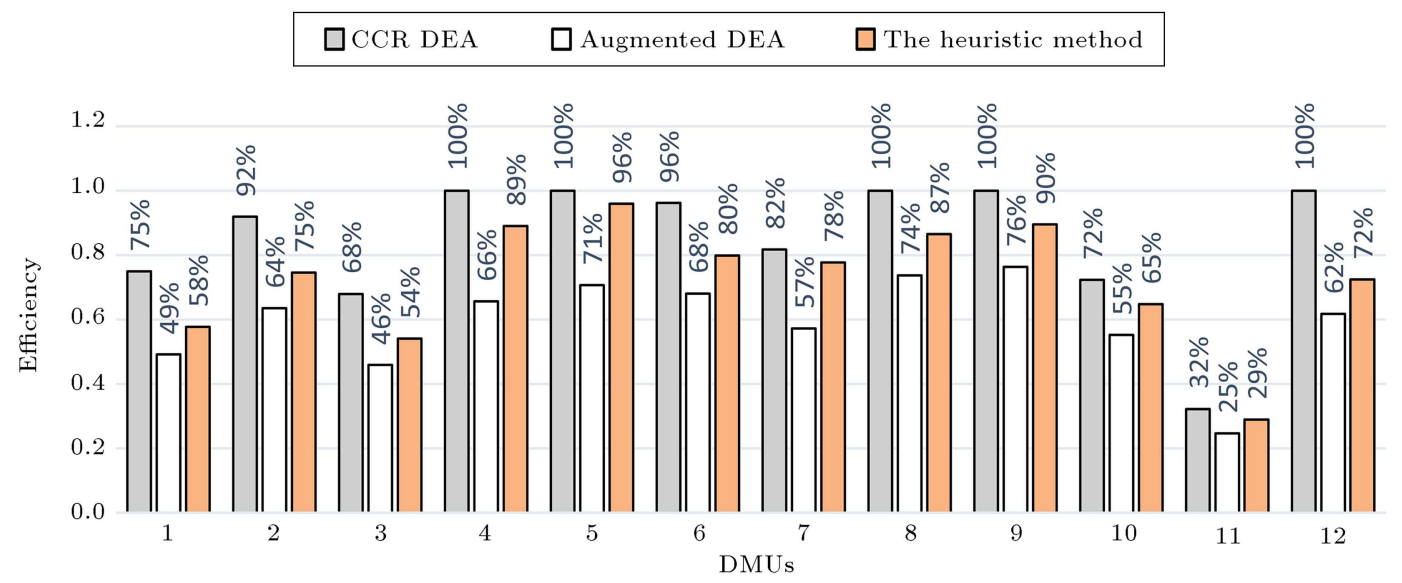

Figure 6. Comparative results of the performance of three approaches towards the efficiency scores of 12 DMUs. 
this method, DMUs do not get unrealistic efficiency scores. In addition, contrary to the augmented DEA, there is less distance between the efficiency scores obtained by this method and those of CCR DEA due to the correct selection of virtual DMUs.

\section{Conclusions}

Today, issues that involve decision support systems and efficiency analysis inside a company require special consideration and several tools have been introduced to assist managers. One of these tools is DEA whose application is expanding in new developments and in research. The problem is that the basic DEA model is usually criticized for its low discrimination power. To overcome this problem, many studies have sought other ways to insert engineering such as virtual Decision Making Units (DMUs) into DEA with the aim of having a set of standard data to evaluate DMUs through simply expanding the reference set. Since different virtual DMUs lead to different results for DMUs ranking, the current study is an attempt to create the best virtual DMUs in order to reduce the possibility of having inappropriate efficiency scores. The main contribution of this study in comparison with the different approaches of handling virtual DMUs is the usage of hierarchical clustering method in order to create a set of potential virtual DMUs in a more coherent manner. The proposed heuristic method in this study can address the problems of adding virtual DMUs to the basic DEA model where DMUs may have unrealistic efficiency scores or great distance with the efficiency scores obtained by the basic DEA. The applicability of the proposed heuristic method is tested by two numerical examples taken form the literature. The results of the proposed heuristic method are compared with the existing methods in past works. The results show that using hierarchical clustering method in DEA for creating virtual DMUs will improve DMU's efficiency over the previous approaches.

Regardless of the type and number of DMUs, the proposed model of this study is applicable to all problems and their discrimination powers need to be enhanced. This property makes the usage of the proposed approach more general and it fits with a large number of real-life and managerial applications. The managerial insights of the proposed method lie in its use to provide a better evaluation ability for organizations to achieve more profitability. Performance evaluation remains as one of the management functions in organizations. However, in order to evaluate performance, it is essential to apply appropriate evaluation tools. The proposed heuristic method in this study allows managers to compare performers for making important evaluation decisions. In addition, incorporating heavy computational efforts such as weight constraints into DEA in order to improve discriminating or ranking of efficient performers may not be interesting from the managerial perspective. The proposed method of this study eliminates such computational efforts and incorporates standards that promote the organizations' ability to evaluate and rank performers.

\section{References}

1. Zegordi, S.H. and Omid, A. "Efficiency assessment of Iranian handmade carpet company by network DEA", Scientia Iranica, Transactions E, Industrial Engineering, 25(1), pp. 483-491 (2018).

2. Rezaie, K., Haeri, A., Amalnick, M.S., et al. "Using augmented dea to calculate efficiency scores of organizational resources", In Computer Modelling and Simulation (UKSim), 2011 UkSim 13th International Conference on, pp. 365-369, IEEE (March, 2011).

3. Haeri, A., Rezaie, K., and Amalnick, M.S. "Using multi-objective DEA to assess the overall and partial performance of hierarchical resource utilization", $R e$ search Journal of Applied Sciences, Engineering and Technology, 5(4), pp. 1213-1224 (2013).

4. Haeri, A. and Rezaie, K. "Using data envelopment analysis to investigate the efficiency of resource utilisation and to develop an improvement plan", International Journal of Productivity and Quality Management, 13(1), pp. 39-66 (2014).

5. Haeri, A. and Ghousi, R. "Using data envelopment analysis (DEA) to improve the sales performance in Iranian agricultural clusters by utilizing business networks and business development services providers (BDSPs)", Journal of Industrial and Systems Engineering, 9(3), pp. 82-95 (2016).

6. Rezaee, M.S., Haeri, A., and Noori, S. "Using data envelopment analysis to evaluate the performances of food production companies based on EFQM's criteria and to present an improvement plan", International Journal of Business Excellence, 14(2), pp. 256-274 (2018).

7. Appalla, R.K. "An augmented DEA for supplier evaluation", Arizona State University, Thesis (2003).

8. Golany, B. and Roll, Y. "Incorporating standards via DEA", In Data Envelopment Analysis: Theory, Methodology, and Applications, pp. 313-328, Springer, Dordrecht (1994).

9. Moslehi, F., Haeri, A., and Gholamian, M. "A novel selective clustering framework for appropriate labeling of the clusters based on K-means algorithm", Scientia Iranica, 27(5), pp. 2621-2634 (2019).

10. Beheshti-Nia, M. and Mousavi, Z. "A new classification method based on pairwise SVM for facial age estimation", Journal of Industrial and Systems Engineering, 10(1), pp. 91-107 (2017). 
11. Granato, D., Santos, J.S., Escher, G.B., et al. "Use of principal component analysis (PCA) and hierarchical cluster analysis (HCA) for multivariate association between bioactive compounds and functional properties in foods: A critical perspective", Trends in Food Science \& Technology, 72, pp. 83-90 (2018).

12. Shokr, I., Amalnick, M.S., and Torabi, S.A. "An augmented common weight data envelopment analysis for material selection in high-tech industries", International Journal of Supply and Operations Management, 3(2), p. 1234 (2016)

13. Shen, W.F., Zhang, D.Q., Liu, W.B., et al. "Increasing discrimination of DEA evaluation by utilizing distances to anti-efficient frontiers", Computers \& Operations Research, 75, pp. 163-173 (2016)

14. Wu, T., Shunk, D., Blackhurst, J., et al. "AIDEA: A methodology for supplier evaluation and selection in a supplier-based manufacturing environment", International Journal of Manufacturing Technology and Management, 11(2), pp. 174-192 (2007).

15. Ghasemi, M.R., Ignatius, J., and Rezaee, B. "Improving discriminating power in data envelopment models based on deviation variables framework", European Journal of Operational Research, 278(2), pp. 442-447 (2019).

16. Wu, T. and Blackhurst, J. "Supplier evaluation and selection: an augmented DEA approach", International Journal of Production Research, 47(16), pp. 4593-4608 (2009).

17. Hou, Q., Wang, M., and Zhou, X. "Improved DEA cross efficiency evaluation method based on ideal and anti-ideal points", Discrete Dynamics in Nature and Society, 2018, Article ID 1604298, 9 pages (2018).

18. Noorizadeh, A., Mahdiloo, M., and Farzipoor Saen, R. "A data envelopment analysis model for selecting suppliers in the presence of both dual-role factors and non-discretionary inputs", International Journal of Information and Decision Sciences, 4(4), pp. 371389 (2012).

19. Kianfar, K., Ahadzadeh Namin, M., Alam Tabriz, A., et al. "Hybrid cluster and data envelopment analysis with interval data", Scientia Iranica, 25(5), pp. 29042911 (2018).

20. Hatefi, S.M. and Razmi, J. "An integrated methodology for supplier selection and order allocation in the presence of imprecise data", International Journal of Industrial and Systems Engineering, 15(1), pp. 51-68 (2013).

21. Mahdiloo, M., Noorizadeh, A., and Saen, R.F. "A new model for suppliers ranking in the presence of both dual-role factors and undesirable outputs", International Journal of Logistics Systems and Management, 15(1), pp. 93-107 (2013).
22. Haeri, A. "Evaluation and comparison of crystalline silicon and thin-film photovoltaic solar cells technologies using data envelopment analysis", Journal of Materials Science: Materials in Electronics, 28(23), pp. 81838192 (2017).

23. Rezaee, M.S., Haeri, A., and Noori, S. "Automotive vendor's performance evaluation and improvement plan presentation by using a data envelopment analysis", International Journal of Engineering, 31(2), pp. 374-381 (2018).

24. Geng, X., Gong, X., and Chu, X. "Component oriented remanufacturing decision-making for complex product using DEA and interval 2-tuple linguistic TOPSIS", International Journal of Computational Intelligence Systems, 9(5), pp. 984-1000 (2016).

25. Ouellette, P. and Yan, L. "Investment and dynamic DEA", Journal of Productivity Analysis, 29(3), pp. 235-247 (2008).

26. Khalili-Damghani, K. and Fadaei, M. "A comprehensive common weights data envelopment analysis model: ideal and anti-ideal virtual decision making units approach", Journal of Industrial and Systems Engineering, 11(3), pp. 281-306 (2018).

27. Allen, R., Athanassopoulos, A., Dyson, R.G., et al. "Weights restrictions and value judgements in data envelopment analysis: evolution, development and future directions", Annals of Operations Research, 73, pp. 13-34 (1997).

28. Pedraja-Chaparro, F., Salinas-Jimenez, J., and Smith, P. "On the role of weight restrictions in data envelopment analysis", Journal of Productivity Analysis, 8(2), pp. $215-230$ (1997).

29. Dyson, R.G. and Thanassoulis, E. "Reducing weight flexibility in data envelopment analysis", Journal of the Operational Research Society, 39(6), pp. 563-576 (1988).

30. Charnes, A., Cooper, W.W., Huang, Z.M., et al. "Polyhedral cone-ratio DEA models with an illustrative application to large commercial banks", Journal of Econometrics, 46(1-2), pp. 73-91 (1990).

31. Thompson, R.G., Singleton Jr, F.D., Thrall, R.M., et al. "Comparative site evaluations for locating a highenergy physics lab in Texas", Interfaces, 16(6), pp. 35-49 (1986).

32. Bal, H., Örkcü, H.H., and Çelebioğlu, S. "A new method based on the dispersion of weights in data envelopment analysis", Computers \& Industrial Engineering, 54(3), pp. 502-512 (2008).

33. Hatami-Marbini, A., Rostamy-Malkhalifeh, M., Agrell, P.J., et al. "Extended symmetric and asymmetric weight assignment methods in data envelopment analysis", Computers \& Industrial Engineering, 87, pp. 621-631 (2015). 
34. Liu, S.T. "Restricting weight flexibility in fuzzy twostage DEA", Computers \& Industrial Engineering, 74, pp. 149-160 (2014).

35. Ennen, D. and Batool, I. "Airport efficiency in Pakistan - A data envelopment analysis with weight restrictions", Journal of Air Transport Management, 69, pp. 205-212 (2018).

36. Wang, Y.M., Luo, Y., and Liang, L. "Ranking decision making units by imposing a minimum weight restriction in the data envelopment analysis", Journal of Computational and Applied Mathematics, 223(1), pp. 469-484 (2009).

37. Ebrahimi, B., Rahmani, M., and Ghodsypour, S.H. "A new simulation-based genetic algorithm to efficiency measure in IDEA with weight restrictions", Measurement, 108, pp. 26-33 (2017).

38. Charnes, A., Cooper, W.W., and Rhodes, E. "Measuring the efficiency of decision making units", European Journal of Operational Research, 2(6), pp. 429-444 (1978).

39. Paura, L. and Arhipova, I. "Advantages and disadvantages of professional and free software for teaching statistics", Information Technology and Management Science, 15(1), pp. 9-64 (2012).

40. Kamis, N.H., Chiclana, F., and Levesley, J. "Geouninorm consistency control module for preference similarity network hierarchical clustering based consensus model", Knowledge-Based Systems, 162, pp. 103-114 (2018).
41. Cook, W.D. and Kress, M. "Characterizing an equitable allocation of shared costs: A DEA approach", European Journal of Operational Research, 119(3), pp. 652-661 (1999).

\section{Biographies}

Marzieh Sadat Rezaei received her BSc degree in Industrial Engineering from Iran University of Science and Technology, Iran in 2014. She pursued MSc degree in 2014 and received it in the same field from Iran University of Science and Technology in 2016. Her research interests include data envelopment analysis, performance measurement, healthcare operation management, and supply chain network design.

Abdorrahman Haeri is an Assistant Professor of Industrial Engineering at Iran University of Science and Technology, Iran. He received his $\mathrm{PhD}$ from the Department of Industrial Engineering, College of Engineering, University of Tehran, Iran in 2013. He holds an MSc in Industrial Engineering, from Sharif University of Technology, Iran in 2008. His main areas of teaching and research interests include data envelopment analysis, network design, and data mining. He has published several papers in international conferences and academic journals. 